REVISTA CHILENA DE LITERATURA

Abril 2009, Número 74, 29 - 56

\title{
LEONARDO PADURA FUENTES Y SU DETECTIVE NOSTÁLGICO*
}

\author{
Clemens A. Franken K. \\ Pontificia Universidad Católica de Chile \\ cfranken@uc.cl
}

RESUMEN / ABSTRACT

Este artículo inserta las novelas policiales del conocido autor cubano Leonardo Padura Fuentes en la tradición tanto del género policial en general como del cubano en especial. Se analiza el perfil psicológico, social e ideológico del investigador principal y protagonista Mario Conde, su método de investigación, su relación con sus amigos, compañeros de trabajo y las mujeres y su fuerte crítica social y cultural. Además, se da especial énfasis a las formas de asimilación (polémica del policial cubano, paródica tanto del género policial clásico del enigma como del género policial negro) en sus novelas policiales híbridas y cada vez más posmodernas.

Palabras Clave: Leonardo Padura Fuentes, novela policial cubana, novela policial híbrida, formas de asimilación en el género policial, crítica cultural cubana.

This article places the detective novels by the well known Cuban author Leonardo Padura Fuentes within the general tradition of detective fiction, as well as within the Cuban tradition. The psychological, social and ideological profile of the novels' main investigator and protagonist, Mario Conde, are analyzed together with his method of investigation, his relationship with friends, workmates, women and his strong social and cultural criticism. Besides, a special emphasis is placed on the forms of assimilation (polemical of the Cuban detective genre and parodical both of the classic mystery detective genre and the hard-boiled detective fiction) in his hybrid detective novels increasingly moving into a more postmodern detective literature.

* Este artículo es fruto del Proyecto Fondecyt Regular 2007 № 1071100 "Hibridaciones, parodias y polémicas con el género policial en la novela latinoamericana". 
KEY WORDS: Leonardo Padura Fuentes, Cuban detective fiction, hybrid detective fiction, forms of assimilation in detective fiction, Cuban cultural criticism.

Desde 1971 surge en Cuba, con un vigor y una amplitud solamente observados en Argentina, una novela policial que, según José Antonio Portuondo, "mantiene los rasgos esenciales del género, pero trae este sentido de identificación de justicia y legalidad socialista y, sobre todo, el concepto de realización colectiva, como autodefensa del nuevo orden social revolucionario" (citado en Rodríguez 62-63).

En los años setenta y ochenta, la novela policial angloamericana experimenta en Cuba una asimilación creativa de parte del pensamiento marxista, cuya antropología considera al ser humano más bien como un producto de las circunstancias económicas, políticas y sociales y, por lo tanto, rechaza al típico detective privado, al margen de los órganos policiales, quien resuelve los problemas gracias a su inteligencia personal. Los autores cubanos lo reemplazan por un investigador que "pertenece a un cuerpo policial, lo representa, y su sagacidad y astucia no actúan de manera independiente, apoyadas solo por su experiencia e intuición, sino en coordinación con las organizaciones políticas y de masas, fundamentalmente con los Comités de Defensa de la Revolución" (Rodríguez 62).

Otra diferencia consiste en el hecho de que, en las novelas policiales cubanas, el origen del crimen "se encuentra en la realidad prerrevolucionaria, es un remanente de la sociedad anterior y como tal debe ser combatido. El delito, más que un atentado a la moral, es un reto a la nueva sociedad, de ahí que, en gran parte de las novelas, se vincula la delincuencia común a la contrarrevolución" (Rodríguez 62) ${ }^{1}$. Esta literatura policial y de contraespionaje cubana, que fue fomentada y también censurada oficialmente a través de

\footnotetext{
${ }^{1}$ Rodríguez Coronel hace un significativo aporte a la comprensión y contextualización histórica de esta novela policial y/o de contra-espionaje cubana, al aportar antecedentes acerca de la novela de espionaje y al situarla dentro del "enfrentamiento de nuestros servicios [cubanos] de Seguridad del Estado, con el apoyo de todo el pueblo, por una parte, y la Agencia Central de Inteligencia (CIA) de los Estados Unidos de Norteamérica, por la otra" (Rodríguez 69). La novela de espionaje surge, según él, después de la Segunda Guerra Mundial y dentro del clima de la guerra fría. Su difusión en el área capitalista ha tenido como propósito principal servir a la lucha ideológica diversionista en contra de los Estados socialistas, las ideas del comunismo y, sobre todo, en contra de la Unión Soviética.
} 
premios literarios anuales, otorgados por el Ministerio del Interior de Cuba, tuvo durante varios años una gran divulgación y numerosos lectores. Según Fernández Pequeño:

[d]urante los ocho años que van de 1971 a 1978 se publicaron en Cuba 12 novelas policiales; sin embargo, entre 1980 y 1983, fue editada la friolera de 22 novelas con este sello; es decir, casi el doble en la mitad del tiempo, y ya se ha dicho con qué calidad promedio. Esa falta de rigor editorial, ese facilismo, otorgó el honor de impresión a textos que nunca lo merecieron, contribuyó a empañar un proceso literario que en la década anterior se había labrado un sitio -no importa ahora si más alto o más bajo- dentro de la literatura cubana de la Revolución y estimuló el descuido y la ausencia de verdadero trabajo creador entre muchos escritores policiales (26).

A estos errores de 'política editorial' se debe agregar la excesiva ideologización y esquematización que provocaron un creciente desinterés en el género durante los años ochenta. La caída del muro de Berlín, el siguiente desencanto en todo el mundo socialista y, ante todo, en Cuba "el proceso de encarcelación y juicios de altos oficiales de las Fuerzas Armadas y el Ministerio del Interior, sucesos que convulsionaron la sociedad" (Michelena 41), hicieron "aumentar la desconfianza y el desencanto en un sistema que se creía inmune a los vicios de la sociedad capitalista" (Vilches 70) y llevaron a un excelente escritor cubano revolucionario y, al mismo tiempo, crítico de los aspectos negativos de la revolución como Leonardo Padura Fuentes (1955), a criticar fuertemente los lados oscuros de la realidad cubana, como se aprecia tanto en su tetralogía policial (Pasado perfecto (1991), Vientos de cuaresma (1994), Máscaras (1997) y Pasaje de otoño (1998)) como en las nouvelles Adios a Hemingway y La cola de la serpiente (2001) y, últimamente, en la novela $L a$

Por su temática -el enfrentamiento entre los servicios de inteligencia de dos naciones o de dos sistemas sociales-, es una novela esencialmente política, lo cual representa una diferenciación básica con respecto a la novela policial sobre la delincuencia común. Precisamente por esta connotación política, la novela de espionaje burguesa se distancia del realismo en la tergiversación del mundo que presenta, ya que es, por su naturaleza, una narrativa donde la ideología del escritor se manifiesta con particular nitidez. Desde este ángulo, la novela de espionaje está siempre al servicio de la lucha de clases en el plano ideológico y mantendrá su plena vigencia mientras existan sociedades antagónicas (68-69). 
neblina del ayer (2006). De esta forma, se ha convertido en un premiado y destacado representante de la nueva narrativa policial iberoamericana.

Cuando Padura

inicia su saga policíaca, [era ya] un escritor y periodista conocido en Cuba. Tenía publicados varios libros de géneros diversos: ensayo, reportaje, entrevista, cuento y novela. [...] Trabajando como periodista había investigado en distintas zonas de la sociedad cubana. En su interés por la literatura policial la había estudiado con amplitud y profundidad, desde Poe y Collins hasta Vázquez Montalbán. En el ámbito nacional era un observador cuidadoso del género y un crítico.

Su ensayo "Modernidad y posmodernidad: La novela policiaca en Iberoamérica" (2000) revela su profundo conocimiento del género policial y resume su postura crítica con respecto a la novela policial cubana de los setenta de la siguiente forma:

Si en la novela policiaca de los otros países de la lengua se imponía una actitud desacralizadora ante el género, y se asumían los cambios de la posmodernidad -artística y social- con una perspectiva audaz, aunque crítica y participativa en la función de sus contenidos, los policiacos cubanos -que en su mayoría debutan en la literatura a través del género- se lanzaron a la creación de una literatura apologética, esquemática, permeada por concepciones de un realismo socialista que tenía mucho de socialista pero poco de realismo. Así, desde los personajes hasta las situaciones funcionaban como entelequías fijas, lo que se hizo más evidente en la figura del 'héroe' -generalmente colectivo, pues se consideraba un hallazgo la 'superación' del investigador solitario-, que respondió más a la realidad de los reglamentos policiacos que a las necesidades dramáticas de la realidad novelesca, más al discurso político oficial que a la creación de conflictos humanos. Mientras tanto, el tratamiento del delincuente o del agente foráneo apenas tuvo espacio en esta novelística, que los definió por simple negatividad política, obviando su valiosa complejidad dramática (153-54).

De las novelas policiales cubanas de los setenta, Padura rescata, sin embargo, El cuarto círculo (1976), de Luis Rogelio Nogueras y Guillermo Rodríguez Rivera -según el destacado crítico literario cubano Rogelio Rodríguez Coronel, "el producto más acabado dentro de las limitaciones que impone 
esta forma novelesca" (65)-, luego "la novela de contraespionaje de Rogelio Nogueras $Y$ si muero mañana, muy en el esquema de los bestsellers internacionales, pero escrito con la dignidad que caracteriza a Rogelio, que era además un gran poeta" (citado en Epple 55) y, ante todo, Joy (1977), de Daniel Chavarría, reconocidas generalmente como las tres mejores de los años setenta.

En estas apreciaciones estético-literarias, ya se nota la formación literaria de este ensayista, guionista de cine, narrador y periodista que, después de recibirse como Licenciado en Filología en la Universidad de La Habana, "se destacó como crítico [literario], precisamente, entre otros intereses, de la narrativa policial" (Rosell 450), lo que corrobora su tomo de ensayos Modernidad, posmodernidad y novela policial. Además, Padura ha publicado otros ensayos literarios, por ejemplo, sobre el Inca Garcilaso y Alejo Carpentier. Lo más relevante es para este trabajo, obviamente, la publicación de su serie de novelas policiales tituladas Las cuatro estaciones, con el teniente Mario Conde como protagonista. Estas novelas tienen como trasfondo temporal las cuatro estaciones climáticas del año 1989, en el cual, según Padura, “[p]or primera vez el descreimiento se hace general" (citado en Epple 58) en Cuba. Los acontecimientos de la primera novela, Pasado perfecto, tienen lugar en el invierno; los de la segunda, Vientos de Cuaresma, en la primavera; los de la tercera, Máscaras, en el verano, y finalmente, los de la cuarta, Paisaje de otoño, en la estación indicada por el título.

Aunque Padura afirma en una entrevista que "[s]alvo dos casos fundamentalmente -Padilla, en el 69-70, y Raúl Rivero, hace dos años-, no ha habido en Cuba escritores que hayan sido reprimidos por lo que han escrito" (1), y que los escritores incómodos más bien han sido marginados, él mismo tuvo problemas con la publicación de su primera novela policial que, según sus propias palabras, "no cumplía las expectativas ideológicas en uso" (citado en Epple 57), y tuvo que ser publicada en México, gracias al apoyo de Paco Taibo II.

En su tetralogía policial, Padura abandona los presupuestos del policial de las dos décadas anteriores que se basaban en la certidumbre y la confianza en los organismos estatales, reemplazándolos por los de la

incertidumbre y el desencanto. Con la tetralogía, Padura logra, como ningún otro escritor en la isla, poner en tela de juicio la efectividad del sistema y develar sus errores. Evidentemente, hay aquí una subversión de las fórmulas que da como resultado que, a pesar de 
que los delitos individuales se resuelven y se castiguen, todavía nos queda la impresión de que el crimen que no ha sido resuelto es el del Estado hacia el individuo. Al referirse a Vientos de Cuaresma, Padura señala su carácter falsamente policíaco: 'los enigmas se resuelven con mucha facilidad. Lo que me interesa es meterme en otros costados de la realidad"' (Rosell 450-51).

Por eso, por una parte, Padura sitúa sus novelas

en esferas de la sociedad que habían permanecido intocadas por los escritores policíacos cubanos. En Pasado perfecto, el -al parecer- brillante director de una empresa estatal es en realidad un dirigente corrupto que se ha enriquecido al amparo de sus funciones y es asesinado por su también corrupto jefe de despacho. Padura delinea [sic], en esta novela, el retrato de un arribista, un hombre que vivió impostando una conducta que lo llevaba a escalar posiciones. En Viento de cuaresma (1994), la víctima, una profesora de preuniversitario que aparenta ser una joven virtuosa, resulta, en la práctica, una mujer de vida sexual promiscua, que mantiene relaciones con el director del plantel y con un alumno al que le facilita las pruebas de los exámenes. En Máscaras (1997), un funcionario de la diplomacia es desenmascarado como impostor vitalicio. En Paisaje de otoño (1998), un ex alto dirigente de la Economía, que vivía en el Exilio, es asesinado al volver al país para intentar llevarse un objeto evaluado [sic] en varios millones de dólares, del cual se había apropiado en el ejercicio de su cargo (Michelena 42).

Por otra parte, Padura se incorpora con estas novelas a la tradición de la novela policial 'anti-detectivesca' (Stefano Tani), cuyos representantes más apreciados son, probablemente, J. L. Borges (cfr. La muerte y la brújula), en América Latina, y Robbe-Grillet (cfr. El mirón), F. Dürrenmatt (cfr. La promesa), Th. Bernhard (cfr. La calera) y U. Eco (cfr. El nombre de la rosa), en Europa.

Padura, no obstante, en concordancia con Paco Taibo II, Manuel Vázquez Montalbán, Ramón Díaz Eterovic y otros escritores y críticos literarios iberoamericanos, prefiere hablar de la nueva narrativa policial iberoamericana o, más bien, del 'neopolicial iberoamericano', que

responde a una nueva realidad de la cual Cuba no está exenta. El propio Padura la define como una novela con mucha conciencia de su función social, y señala que tiene la necesidad 'de expresar problemas 
de la realidad actual de nuestros países: la corrupción, el arribismo político, los problemas de la droga, la prostitución, la marginalidad' (Epple 60). Al mismo tiempo, Padura [...] [r]econoce, asimismo, que este policial se inserta dentro de la posmodernidad por su intencionalidad irónica y paródica y por la voluntad expresa por parte del autor de transgredir las funciones del género (Rosell 451).

En la entrevista realizada por Epple, Padura agrega luego otro aspecto fundamental del neopolicial: "Los policías, investigadores, detectives, como se les llame, son por lo general gente frustrada, jodida, y no tienen nada de triunfadores" (60).

Aunque lo dicho por Padura está presente en todas sus novelas nos concentraremos, sin embargo, ante todo, en Máscaras, probablemente su mejor novela (neo)policial, la cual, siendo una "interpretación heterodoxa del género negro", obtuvo, según "la asociación Novelpol (dedicada a la novela policial)", el lugar catorce entre "las veinte novelas policiales que todo aficionado al género debía haber leído" (Uxó, "Introducción" 9). Es decir, Padura ya es reconocido como uno de los grandes y más relevantes del género policial ${ }^{3}$. En esta novela, Padura critica la forma como el estado cubano persiguió y marginó a los homosexuales y cuya figura investigadora, el teniente Mario Conde, según Michelena, "el primer gran personaje creado por la literatura policial cubana" y con "una identidad de indudable cubanía (lenguaje, gustos, comportamiento, sistema de valores)" (45), cumple perfectamente con las características respectivas recientemente expuestas por su creador.

De hecho, este policía, con evidentes rasgos "de los detectives Marlowe, de Raymond Chandler, y Carvalho, de Manuel Vázquez Montalbán [...], [e]s un policía completamente atípico, tanto en la realidad como en la anterior literatura policial cubanas" (Michelena 45), que tiene en 1989, es decir, en las novelas de Las cuatro estaciones, treinta y cinco años, con diez años de

2 En la entrevista de Carlos Uxó, Padura revela que su "forma de escribir 'policiales' no es ortodoxa, porque él trata "de ser lo más heterodoxo posible en cuanto a lo establecido por las viejas normativas del género" (31).

3 La razón de este lugar destacado de Padura dentro del género policial consiste en el simple hecho de que él es un gran escritor. De hecho, nunca se "consideró un autor de "policiales', sino un escritor" (citado en Uxó, "Entrevista..." 34). La gran cantidad de premios ganados por él corroboran, en cierta medida, el alto nivel estético-literario de su obra artística (cfr. Uxó, "Introducción" 13-14). 
trabajo en la Central de Policía de La Habana. Ha sido recientemente suspendido por una bronca con un colega, a pesar de que su admirado jefe, el 'viejo' mayor Antonio Rangel, lo considera el mejor entre sus colaboradores. Lo que más le preocupa al Conde actualmente es, aparte de su calvicie amenazante, la vida de 'lobo solitario' que lleva sin mujer y sus frecuentes resacas. Él siente, aparte del "calor solitario de su casa" (Máscaras 13), un miedo y un vacío existenciales que no logran superar y/o llenar ni sus frecuentes recuerdos nostálgicos y melancólicos del pasado, como, por ejemplo, de su querido abuelo 'Rufino el Conde', de su Primera Comunión hace veintiocho años, de las misas dominicales a las cuales su padre lo obligaba ir, de los partidos de fútbol con sus amigos del barrio, del tiempo dorado de los estudios universitarios en la 'Pre', que lamentablemente quedaron inconclusos, de sus serios intentos de convertirse en un 'verdadero escritor' y de la gran frustración cuando las autoridades culturales suspendieron la revista literaria, en la cual había publicado su primer cuento, acusándolo a él y a sus compañeros "de escribir relatos idealistas, poemas evasivos, críticas inadmisibles, [e] historias ajenas a las necesidades actuales del país, [...]” (Máscaras 59). Con razón, su mejor amigo, el Flaco Carlos, herido tan gravemente en África como soldado voluntario de la revolución, que ahora vive prácticamente en una silla de ruedas y ya no es nada flaco, lo llama "un cabrón sufridor, un incorregible recordador, un masoquista por cuenta propia, un hipocondríaco a prueba de golpes y el tipo más difícil de consolar de los que había en el mundo, [...]" (Máscaras 15).

Sin duda, lo que le hace la vida psicológicamente soportable al teniente Mario Conde es la amistad, ante todo la con el Flaco, cultivada intensamente desde hace veinte años cuando eran felices estudiando juntos en las tardes, oyendo música e imaginándose un futuro promisorio como ingeniero y escritor, respectivamente. El grado de profundidad de esta amistad se revela, ante todo, en que sobrevivió a todos los golpes duros de la vida durante casi veinte años. Por eso, Mario se siente más un hermano que un amigo del Flaco $\mathrm{y}$, a diferencia de éste, que teme un reencuentro con su ex pareja Dulcita, Mario espera y, en cierta medida, exige de ella, que se fue a los EE.UU. y que quiere ver al Flaco ahora sin saber de su actual estado de salud, la misma fiel e incondicional amistad que reina entre ellos. Lo comprueban sus siguientes palabras:

- Flaco: no seas maricón -le dijo- . No te dejes vencer, cojones, que si tú renuncias sí que estamos jodidos. Hazlo por ti, y por mí y por la 
vieja Josefina: no dejes que nada te joda: ni una bala, ni el pasado, ni la guerra, ni esta cabrona silla de ruedas -soltó sin respirar y, contra su costumbre de pensarlo todo, tomó con sus manos la cara de Carlos y lo besó en un carillo-. No renuncies, mi hermano (Máscaras 111).

El hecho de que Mario Conde valoriza esta gran amistad con el Flaco incluso por encima de la "responsabilidad ética como revolucionario" (Fernández 6) queda de manifiesto en la visita de ambos a 'la piloto' ilegal ${ }^{4}$ de Candito el Rojo, un amigo de ambos. A pesar de que el Conde se negó al comienzo a esta visita por ser policía y parte del poder oficial, cede, al final, a los ruegos irresistibles de su mejor amigo. La amistad aparece aquí y en el episodio anterior, como el valor supremo de la vida y el principal remedio valedero contra todas las adversidades.

Por eso, Mario Conde la cultiva también con otro viejo amigo, Candito el Rojo, quien "le había demostrado una fidelidad permanente, a la que el Conde no había correspondido con la misma sinceridad", sintiéndose "cínico y egoísta" (Máscaras 120). En cierta medida, Mario le retribuye su fidelidad al advertirle-como amigo y contra su deber como policía-que debe "quitar la piloto" (Máscaras 121), es decir, cerrar su negocio ilegal de cerveza, porque la Policía Interna ya sabe de su existencia.

Un alto grado de amistad mantiene el Conde también con su colega, el capitán Contreras, quien es la primera víctima de las pesquisas de la Policía Interna en la Central de Policía. Mario siente de repente "la fatalidad de ciertos destinos" (Máscaras 139) y luego la necesidad de hablar con el Gordo Contreras y, contra la resistencia de su ayudante, el sargento Manolo Palacios, logra ser "el primer hijo de puta policía que [va] a ver[lo] ..." (Máscaras 141), para manifestarle su compasión. Luego, cuando su jefe, el mayor Antonio Rangel, descalifica al Gordo Contreras como el responsable del hecho de que lo "van a registrar hasta los pelos", el Conde sencillamente se resiste a creerlo y considera estas acusaciones "una mierda que le quiere hacer esa gente" (190) de la Investigación Interna.

A pesar de este desacuerdo con el 'Viejo' respecto a la persona del capitán Contreras, a Mario Conde también lo une una gran amistad con su jefe. Ambos sienten lealtad el uno por el otro y, en lo posible, se tratan con respeto y hasta

4 Se trata de "una especie de bar - que opera en los márgenes del socialismo en Cuba" (Fernández 6). 
con cariño. Por ejemplo, el Conde, siendo un gran fumador de cigarros, le da un buen Montecristo que le regaló Faustino Arayán, el alto funcionario y diplomático del régimen castrista y, además, padre e infanticida del malogrado Alexis, una vez que se enteró que el 'Viejo' estaba fumando cigarros malos y se molestaba por esta realidad insólita en un país famoso por sus buenos puros. En Paisaje de otoño, la lealtad al jefe y amigo lleva a Mario Conde a renunciar a la policía, debido a que una serie de irregularidades cometidas por sus compañeros le cuestan la salida a su admirado jefe. Es por eso que cuando el nuevo hombre a cargo de la Central, el coronel Molina, le exige la resolución del caso Forcade como condición para firmar su baja, el teniente Mario Conde duda y prefiere consultar ante todo a su ex superior, pues no quiere sentir que está traicionando una confianza de años. Luego de renunciar, Mario Conde se encierra tres días completos a beber, fumar y esperar la venida del ciclón Félix, fenómeno que irá de la mano con los cambios que sufre el personaje durante los pocos días previos a su cumpleaños número treinta y seis. Al tercer día, son sus amigos los encargados de buscarlo en su casa, de sacarlo de la soledad y el hambre del que era presa y de celebrar su cumpleaños en la medida de sus posibilidades, entregando lo mejor que tienen para la felicidad de Mario Conde. De hecho, la novela no termina con la resolución del asesinato de Miguel Forcade, sino con la celebración que los amigos le hacen la noche de su cumpleaños (cfr. Pasaje de otoño 210ss).

Además, un canto diferente y muy lindo a la amistad digno de mencionar es en esta novela la relación humana entre Mario Conde y el artista homosexual Alberto Marqués, la cual se transforma desde un recíproco rechazo mutuo al comienzo, pasando por el creciente respeto, hasta sentimientos amistosos y solidarios al final. Probablemente, el mensaje que Padura quiere entregarnos en esta novela es el de que, conociéndose y abriéndose el uno al otro, los hombres son capaces de respetarse e, incluso, convertirse en amigos, superando, así, las diferencias culturales. De hecho, Mario Conde, el 'machista-estalinista' que rechazaba casi visceralmente a los 'maricones', siente, al final, respeto por el trágico destino del artista homosexual Alberto Marqués, y le pide perdón por su maltrato anterior, sintiéndose solidario con él. Marqués, por su parte, logra superar su anterior rechazo a cualquier policía, aprecia las dotes artísticas del cuentista Mario Conde y siente, al final, cierta cercanía y simpatía por él.

También la relación del teniente Conde con su colaborador, el sargento Manuel Palacios, se caracteriza por lazos amistosos que van mucho más allá de los usuales en el género policial, por ejemplo, los clásicos angloamericanos 
de Sherlock Holmes con el Dr. Watson e, incluso, los hispanoamericanos del teniente Silva con el guarda Lituma en ¿Quién mató a Palomino Molero? de M. Vargas Llosa. Hay una gran confianza y simpatía mutua entre los dos que son la base sólida de su relación amistosa profesional. Ambos desean lo mejor para el compañero y se protegen mutuamente. Por ejemplo, el Conde le comunica su preocupación por la cita de Manolo con la Policía Interna, y Manolo, por su parte, le advierte más adelante y en forma amistosa, de andar con más cuidado. Ambos se conocen muy bien tras años de trabajo policial en común y, además, se estiman. De hecho, el Conde reconoce incluso que Manolo es "mejor policía" (Máscaras 65) que él mismo y le suele pedir siempre primero su opinión, algo que también hacía Sherlock Holmes con el Dr. Watson. Esto explica que ambos forman un equipo de policías amigos con prácticamente las mismas capacidades y los mismos derechos y sin la tan conocida relación jerarquizada entre jefe y súbdito. Es decir, Manolo no es aquí el narrador de los sucesos policiales que cumple la tradicional función de representar el sentido y la inteligencia común del lector para destacar, así, aún más, la genialidad del gran detective. Al contrario, Manolo discute a menudo el caso con su jefe amigo, lo critica abiertamente e, incluso, se enoja con él agrediéndolo verbalmente. Esto sucede, por ejemplo, cuando el Conde termina abruptamente un interrogatorio agresivo y duro realizado por Manolo que el Conde le había pedido por considerarlo un mejor interrogador que él mismo. El alto grado de amistad se manifiesta, sin embargo, nuevamente en el hecho de que Manolo le pide, al final, perdón por sus agresiones verbales.

El éxito del Conde en la construcción y el cultivo de lazos amistosos duraderos con hombres, lamentablemente, no se da en su relación con las mujeres. Ya se ha dicho que vive solo y que anhela la cercanía de una relación afectiva más estable. En la lista de sus amores perdidos, la relación con Tamara fue la más constante, a la cual siguieron las más bien furtivas con Karina, Haydée y Maritza, las que recuerda nostálgica y desesperadamente. En Vientos de cuaresma, es la pelirroja Karina quien lo flecha de inmediato y lo hace enamorarse en solo tres días, tener sexo intenso y sentirse nuevamente vivo hasta que descubre que ella está casada y que ya no lo puede seguir viendo, lo que lo destruye y lo hace enfrentarse a sí mismo tras las palabras finales de esta mujer: "[...] escogí al peor hombre del mundo. - ¿Soy el peor? -Te enamoras Mario" (Vientos de cuaresma 202). Por esto se verá enfrentado a sus emociones hacia las mujeres siempre luchando entre sus ganas de enamorarse y el deseo de solo disfrutar de ellas. 
En la novela Máscaras, después de "dos meses a dieta manual" (126), es decir, de masturbaciones ocasionales, su objeto deseado es Poly que, al igual que Karina, "no era linda ni poblada de encantos carnales visibles", pero que "caía en la categoría de objeto singable de primer grado, según la devaluada exigencia erótica del Conde" (Máscaras 128). Con ella pasa una noche entera con todo lujo de detalles comenzando con el desvestirse y la felación. El recuerdo de esta noche lo hace capaz de renunciar algunos días más tarde a la masturbación ${ }^{5} \mathrm{y}$, por otro lado, lo anima a prepararse bien para una fiesta erótica de tres días con la Poly, al final de la novela.

Sin embargo, en la última novela de su tetralogía, la relación de nuestro descuidado y aparentemente poco atractivo protagonista con las mujeres experimenta cambios en un doble sentido: en primer lugar, durante la investigación conoce a Miriam, la esposa del difunto Mario Forcade que se encontraba de paso en Cuba junto a su marido muerto. Al contrario de lo que cree el lector acerca del Conde, tarde o temprano terminará involucrándose sexualmente con esta mujer atractiva, cuya cabellera de un rubio falso y cuyos senos y muslos constantemente está observando con un fuerte deseo, él sabe que no puede confiar ni enamorarse de una mujer teñida de rubio y pese a que se pone a cantar boleros (lo que hace cada vez que está enamorándose), no cede a sus pasiones y mantiene su profesionalismo. En segundo lugar, y tal vez como premio a su sensatez, al final de la novela aparece Tamara, una antigua compañera de colegio, de la cual Mario Conde sigue enamorado y con la cual "sería capaz de casar[se] por la iglesia" (222), la que sorpresivamente le reclama su compañía. Lo que sorprende, en este contexto, es que la soledad del teniente es tan grande que pareciera que quisiera escapar de un amor posible y declarado:

- No seas estúpido, Mario: ¿no te das cuenta de que estoy sola, de que me haces falta? Alguna vez deberías ser menos egoísta y pensar en las cosas que le pasan a los demás [...].

5 Según Genaro Pérez, a través de la tetralogía se puede observar un Mario Conde "enamorándose para ser abandonado después de breves encuentros. Probablemente tales traumas causen su obsesión con el onanismo. En Paisaje de otoño hay una especie de tipología de las diferentes maneras de masturbarse" (112). Más que de una obsesión, me parece apropiado hablar de una dependencia o necesidad fisiológica y psicológica. 
- No hables así, Tamara: no estoy acostumbrado a hacerle falta a nadie. Ni a mí mismo -y es él quien la besa, con la brevedad impuesta por una despedida indeseable pero necesaria-. No te preocupes, mañana vengo (223).

Parece que, al final de la tetralogía, Padura quiere dejar a su protagonista en una relación amorosa más estable, lo que éste siempre anhelaba profundamente.

Esta postura moral vacilante en la relación del Conde con el sexo femenino se presenta también en su concepto de la verdad, dado que la concibe, en primer lugar, dentro de la tradición platónica como 'aletheia', es decir, como un proceso o acontecimiento de desocultamiento, desvelamiento o descubrimiento. Ya que sabemos que "los textos de Padura buscan revelar la realidad escondida tras un sistema engañador" (Vilches 65). Por ejemplo, en la mitad de la investigación de su tercer caso, Mario Conde siente que "la verdad de la muerte de Alexis Arayán [estaba oculta en la hoja de la Biblia]" (Máscaras 147). Pocas páginas más adelante, dice intentar "arrancar la máscara tras la que se ocultaba la verdad", la que caracteriza luego como "[s]iempre escondida o transfigurada" y "cabrona" (Máscaras 159), es decir, difícil de descubrir y encontrar. Por eso, al final de la novela y a pesar de que el caso quedó perfectamente aclarado como en cualquier novela policial clásica tradicional, el Conde sostiene "que nunca se sabría toda la verdad" (Máscaras 197). Aquí se ve más claramente que, hasta este momento, la postura posmoderna de Padura que parte del principio de "la incertidumbre y el desencanto" (Rosell 450), no es tan radical como, por ejemplo, la de Borges, que a diferencia de Padura hace fracasar, en último término, a su detective E. Lönnrot en la búsqueda de la verdad.

Sin embargo, en Adiós, Hemingway, su postura posmoderna predomina en forma más nítida, dado que el "Conde nunca llega a saber quién es el asesino del presunto agente del FBI cuyos restos aparecen en Finca Vigía. Y prefiere no saberlo, pues presiente que puede ser doloroso" (Padura citado en Uxó, "Entrevista..." 34).

Algo parecido ocurre con la postura moral del Conde frente a la justicia, la que hay que comprender dentro de la tradición policial negra que destaca la dificultad de que la verdad encontrada también se imponga y que se haga justicia. Mario Conde se convirtió en "policía únicamente porque no le gusta que los hijos de puta puedan hacer las cosas impunemente" (Padura citado en Epple 57), y "cree que en el fondo de todo debe existir la justicia y la 
verdad, pues de lo contrario viviríamos en la selva" (Padura citado en Uxó, "Entrevista..." 32). Consecuentemente, en la novela Máscaras le ha pedido al 'Viejo' no tener compasión con el criminal Faustino Arayán. Además, por su sentido de justicia, le encantaría estar presente "cuando le fueran arrancando las tiras de la máscara que, al final, se había convertido en su propio rostro" (Máscaras 192). Pero, lamentablemente, le toca ver que este 'pez gordo' recibirá un trato especial: antes de que dos policías de civil lo arresten, el mayor Rangel tuvo que informar o, más bien, consultar a una autoridad superior. Queda, por lo tanto, la sensación de desigualdad frente a la ley y tal vez también de un cierto grado de impunidad tan frecuente en las novelas policiales negras hispanoamericanas.

Además de esta obstaculización institucional a la implantación de la justicia, se agrega ahora tanto en Adiós, Hemingway como en La neblina de ayer un problema de índole filosófico-jurídico, es decir, una creciente simpatía posmoderna por el criminal, la que Padura justifica con el hecho de que

no siempre el criminal, el ejecutor de un crimen, es el culpable de lo que ha ocurrido. Y déjame recordarte que ya esa sensación aparecía en novelas como Vientos de cuaresma y Paisaje de otoño ${ }^{6}$, que le dejaban a Conde el mal sabor de boca de haber encontrado un asesino que debía haber sido asesino. [...] Y al encontrar al 'criminal' [...] en La neblina del ayer lo único que hace es hallar una historia de dolor y frustración que parece un equívoco. Tal vez en esta actitud hacia 'lo criminal' yo me aleje de la moraleja clásica de la novela policial, que tiene un origen marcadamente burgués y una filosofía totalmente burguesa, y me acerque más a otras actitudes en las que el destino, lo humano, la fatalidad tienen un peso mayor, como ocurre en Edipo rey (obra que adoro) o en Crimen y castigo. [...], y las moralejas éticas me dan pavor: por eso Conde puede ser amigo de delincuentes, incluso, delinquir él mismo para poder vivir o sobrevivir, pero siempre sin perder esa humanidad, ese sentido

6 En Paisaje de otoño, por ejemplo, cuando ya se sabe al final de la novela que Adrián Riverón fue el asesino de Miguel Forcade, el Conde se lamenta de su suerte, pues de los involucrados en el caso, Adrián Riverón era el menos culpable y quien finalmente no actuó completamente movido por el dinero sino también por la pasión. Mario Conde hubiera preferido ver en la cárcel a personas como Gómez de la Peña, hombre que se jacta de tener un Matisse original en su casa y enriquecido durante el régimen, o a Fermín Bodes, el hermano de Miriam, quien estuvo en la cárcel por malversación de dineros públicos. 
de los límites que le permiten seguir siendo una persona íntegra a pesar de cometer u ocultar ciertos delitos. $Y$ es que su capacidad de comprender la vida (en ese caso la vida cubana) va más allá de una ética inviolable, pues él sabe que muchas personas en Cuba, durante muchos años, han debido colocarse al margen, o más allá, de lo legal para vivir (citado en Uxó, "Entrevista..." 34).

De esta forma, Padura se acerca, claramente, a posturas que por ejemplo G. García Márquez muestra en su novela Crónica a una muerte anunciada.

Algo posmoderna y escéptica es también la postura del Conde frente a la fe y la Iglesia. Ya sabemos que su padre lo hizo ir a las clases de catecismo y hacer la Primera Comunión, lo que el Conde considera ahora, veintiocho años después, una ventaja porque le entregó la información de que este importante día del " 6 de agosto [era] la Fiesta de la Transfiguración para los católicos", en la cual la Iglesia Católica celebra el hecho de fe que Jesús se transformó delante de sus discípulos y Dios Padre manifestó expresamente su amor a su hijo amado. Este saber religioso le otorga al Conde la posibilidad de asociar esta fecha litúrgica con el hecho, según él nada casual, de "que aparezca un travesti muerto un 6 de agosto [...]" (Máscaras 30-31). A pesar de que duda acerca de la existencia de Dios, ante todo, por el problema de la teodicea, es decir, de la existencia del mal en este mundo, y a pesar de que hace años no va a la Iglesia, anima, sin embargo, a aquellos de sus amigos, como Candito el Rojo, que sí creen, a ir a la Iglesia y rezar también por él. Esta posibilidad de que Dios existiera es probablemente también la causa de que el Conde mantuvo durante años "una relación afable" con el cura Mendoza, quien lo considera, por una parte, un "disidente" y "místico sin fe" y quien, por otra parte, lo acusa de "arrogancia" y "miedo a [sí] mismo", pronosticándole "que algún día caer[á]...” (Máscaras 74).

Esta postura algo escéptica, pero claramente no atea del Conde se refleja también en su cercanía espiritual con el viejo poeta católico cubano Eligio Riego $^{7}$ que practica un catolicismo nada místico ni beato y que sabe disfrutar de la vida, es decir, "tom[a]ron en cantidades considerables, fum[a] [sus]

7 Detrás de la persona de Eligio Riego se esconde, probablemente la del conocido poeta, crítico, ensayista y novelista cubano católico Cintio Vitier (1921). 
pipas, y nunca $\mathrm{h}[\mathrm{a}]$ podido negar[se] a la contemplación a veces desesperada de una muchacha en flor" (Máscaras 165) ${ }^{8}$.

En Paisaje de otoño, Mario Conde sufre aún más la ausencia de Dios como carencia y como vacío existencial. Es por eso que este tema se torna importante en una parte de la novela, cuando uno de sus amigos decide acercarse a la Iglesia y alejarse de la delincuencia y el alcohol. Inicialmente, hay una mirada estereotipada al catolicismo y sus templos. Sin embargo, su postura cambia cuando entra a una iglesia protestante a buscar a su amigo Candito y se enfrenta a otro tipo de actitud y de arquitectura. Así el narrador señala:

Y lo que vio le pareció conmovedor: aquella iglesia nada tenía que
ver con los conceptos de iglesia almacenados en el cerebro católica-
mente entrenado del Conde. Para empezar, faltaba el altar, siempre
precedido por la imagen del santo rector del templo, pues sobre la
pared limpia, blanqueada con cal, solo colgaba una rústica cruz de
madera sin ningún Cristo sacrificado sobre ella (Paisaje de otoño
75-76).

La visión de un espacio desprovisto de adornos y de un grupo de fieles que gritaban entusiasmados motivados por un negro bajito sin sotana, le causa un gran impacto y hace surgir en él una reflexión profunda sobre su "evidente incapacidad de pertenencia a aquella horda de creyentes y salvables" (Paisaje de otoño 76).

De este modo, la duda empieza a inundar los pensamientos del teniente: “¿quién estaba equivocado: él o todas las personas reunidas dentro de esa iglesia sin altares ni Cristos? ¿Aquellos que creían en algo capaz de salvarlos o él, que apenas si creía en un par de cosas que podían ser salvables?" (Paisaje de otoño 76).

Mario Conde contrasta en este novela su propia falta de fe y su soledad con la visión del grupo y la fe de su amigo, para el cual resulta mejor hablar

8 Eligio Riego, al igual que su amigo Alberto Marqués, tuvo que acatar "el silencio pero no dej[ó] de escribir" (Máscaras 166). Además, profesa "dos fidelidades inalterables en [su] vida: la amistad y la poesía" (Máscaras 167), los valores que también el Conde, como vimos arriba ante todo respecto al primero, estima como los más relevantes en la vida. De la segunda, dice Alberto Marqués al final de la novela que es "invencible" (Máscaras 205) y perdurará en el tiempo mientras que pronto nadie se acordará de los nombres de los funcionarios culturales que la silenciaron. 
de fe, amor, esperanza y salvación, “oyendo decir lo que no se dice en ninguna parte y dicho por gentes que creen en lo que dicen. Eso es mejor que vender cervezas o comprar piel robada para hacer zapatos ¿o no?" (Paisaje de otoño 77).

Pero la piedra de tope de Mario Conde es el perdón. Solo allí el teniente se reconoce "muy jodido", porque para él "hay cosas que no se pueden olvidar" y las que tampoco está dispuesto a perdonar. Además reconoce que "a veces no cre[e] ni en [s]í mismo" (Paisaje de otoño 78-79). No obstante, el Conde comprende a su amigo e incluso lo respeta y lo envidia en esas circunstancias, por la fe y la visión que profesa en aquel momento.

Ocho años más tarde, en el tiempo narrado de Adiós, Hemingway, Mario Conde parece acercarse más aún a las creencias de sus amigos porque, según Armando Epple, "predomina ahora un sentimiento de desamparo y nostalgia por el pasado, junto a la necesidad de aferrarse a algunas convicciones que le den sentido a la vida" (2006: 172).

En su última novela, La neblina del ayer, por su parte, Padura, según sus propias palabras, ya no tematiza el desencanto y el agotamiento de una creencia, sino "la nostalgia y [...] la necesidad de creer en algo, y por eso Conde incluso coquetea con lo intangible, con lo esotérico... pero sin dar el paso definitivo" (citado en Uxó, "Entrevista..." 30). Podemos constatar, así, una creciente preocupación de Mario Conde por la problemática de la fe que va acompañada de una falta de crítica a la Iglesia Católica. Aparentemente tendremos que esperar la aparición de la siguiente novela para saber si finalmente se cumple el pronóstico del cura Mendoza.

$\mathrm{Al}$ igual que en esta temática nada específicamente negra que recuerda más bien el hecho de que Mario Conde "se considera colega del Padre Brown de Chesterton" (Vilches 73), también en su metodología de investigación el Conde casi no asimila elementos negros, sino observaciones, deducciones y abducciones (conjeturas, hipótesis) y presentimientos, todos elementos que son más bien características de la investigación del detective clásico del enigma, como, por ejemplo, Sherlock Holmes o el Padre Brown. Solo el elemento de la interrogación lo comparte también con los detectives 'duros'.

Respecto a la observación, hay que destacar, sin embargo, que en Máscaras, al teniente Mario Conde no le resulta para nada agradable el discurso positivista del forense, aunque acepta sin vacilar los resultados de sus investigaciones de las huellas en el lugar del crimen y de la autopsia: la genuflexión de Alexis, la presencia de un hombre grande entre cuarenta y sesenta años, el hecho de que lo mató un hombre manco con grupo de sangre determinado 
y que el travesti no forcejeó, etc. Todos estos datos científicos le son muy útiles. Ante todo, obviamente, la comprobación del laboratorio de que los tres pedazos de cigarros tienen el mismo origen, es decir, que son de la marca Montecristo que fumaba Faustino Arayán, quien queda, así, identificado como asesino de su propio hijo. Esta comparación de los tres tabacos le parece a Alberto Marqués una deducción genial del Conde que se basa justamente en una aguda observación digna de Sherlock Holmes, que sabía distinguir entre unos sesenta tabacos diferentes.

El Conde, en general, es presentado como una persona que piensa mucho y nunca usa la fuerza física o la violencia tan característica para el detective 'duro'. Al contrario, Mario Conde, siguiendo la forma de investigar del Padre Brown y del comisario Maigret, intenta comprender más bien las actuaciones del malogrado Alexis Arayán desde adentro. En Máscaras, por ejemplo, para lograr una cierta empatía con la víctima, el Conde inventa algunas hipótesis, suposiciones y conjeturas acerca de las causas desconocidas de los hechos observables, que Umberto Eco ${ }^{9}$ y otros han llamado abducciones, es decir, deducciones hacia atrás o retroducciones. La más relevante, que al final se impondrá como verdadera, es la que asocia, como ya vimos arriba, el día de la muerte, -o mejor dicho del suicidio, del travesti Alexis Arayán, odiado por su padre-, con la fiesta litúrgica de la Transfiguración de Jesús, en la cual éste, según el credo cristiano, se transforma y Dios Padre le manifiesta su amor. Varias veces, durante el transcurso de la investigación, el Conde retoma su hipótesis e, igual a Erik Lönnrot en el cuento borgeano "La muerte y la brújula", lee mucho y sigue hasta el final con esta suposición basada en su rica imaginación poética presente también en sus cuentos, obteniendo finalmente la solución del problema.

En Paisaje de otoño queda muy claro que las suposiciones del Conde son más bien intuiciones. De hecho, en esta novela, Mario Conde termina pidiéndole ayuda al padre del asesinado Miguel Forcade, un anciano capaz de leer los estados anímicos de las plantas y de leer la mente de algunas personas, al igual que A. Dupin, el Padre Brown y Maigret. Junto a esto, cuando

9 Los autores Bonfantini y Proni sostienen en su capítulo "To guess or not to guess?" del libro, que "Holmes lleva a cabo varios tipos de operaciones: por una parte, observa, por otra, concluye, infiere, formula hipótesis en suma, construye teorías, y después encuentra y organiza hechos que confirman estas teorías" (169). Luego hablan de la formulación de hipótesis y de conjeturas como "retroducción o abducción" (172s). 
el Conde está a punto de resolver el caso siente una punzada en el pecho que lo lleva al culpable, punzada que desaparece cuando la prueba del delito, un bate de beisball, aparece en la casa de Adrián R., el asesino. En esta novela, el mismo Conde reconoce que su método de investigación es principalmente intuitivo: "Aunque con frecuencia acudía a la rutina investigativa, cada vez más su metodología se basaba en presentimientos, prejuicios y chispazos que en razonamientos estadísticos o conclusiones de lógica estricta, y por eso prefería dejar a sus auxiliares el lado científico de la investigación" (99) ${ }^{10}$. Estamos, por tanto, ante una metodología que mezcla deducción/abducción con intuición y por eso parece algo exagerado concluir que "[e]l método de investigación del Conde es ya una carnavalización de la ciencia de la investigación criminal" (Michelena 46).

El tercer rasgo más relevante de su método investigativo es el interrogatorio, un elemento común tanto de la novela clásica como de la negra. Junto con el sargento Manuel Palacios, el teniente Mario Conde interroga en Máscaras a Alberto Marqués, a Salvador K., el pintor y última pareja de Alexis, al Padre Mendoza, a Faustino Arayán y a la criada María Antonia que, al final, les entrega la información más valiosa para la solución del caso, a saber: el pantalón de Faustino Arayán sucio en el borde de abajo y con dos restos de tela roja en un bolsillo, la medalla devuelta, el cigarro Montecristo, etc. El hecho de que las informaciones de esta persona humilde son decisivas para la aclaración del caso y no la inteligencia genial del Conde o su capacidad de observación, deducción e interrogación, comprueba, por un lado, que Padura no está dispuesto a abandonar totalmente el estereotipo de la novela policial cubana anterior a él, en el sentido de que la solución del problema debe ser también colectiva y no solamente individual como sucede en las novelas policiales clásicas y negras. Por otro lado, este mismo hecho revela su asimilación polémica del género policial cubano, dado que no son miembros de las CDR (Comité de la Defensa de la Revolución) los que ayudan a resolver el caso motivados como funcionarios del orden y del poder, sino una persona particular motivada por razones personales. "María Antonia delata a Faustino Arayán por su devoción maternal hacia Alexis y no por un sentido

10 En la ya menudo mencionada entrevista de Carlos Uxó, Padura confirma al respecto que el "Conde actúa más con pasión que con inteligencia, más con amor o dolor que con métodos de investigación policial científica, y sus recursos son las premoniciones, los presentimientos, los chispazos de clarividencia, reacciones todas muy pasionales" (27). 
de deber hacia la revolución, el socialismo o el pueblo, como se intentaba hacer en las obras que caracterizaban la policial de los setenta" (Fernández 8-9). De esta forma, María Antonia subvierte el vínculo ideológico entre los CDR y el gobierno en la novela policial revolucionaria ${ }^{11}$. Padura se aleja, así, de sus precursores cubanos y, al mismo tiempo, con su crítica a los ricos y poderosos políticos cubanos en contraste con los cubanos pobres y buenos, se acerca a los autores negros norteamericanos clásicos.

Con estas observaciones, entramos de lleno al campo de la crítica social, cultural y política de la sociedad y del Estado tan característica para el género policial negro. En el caso de Padura, su denuncia se concentra, ante todo, en cuatro aspectos más bien políticos: los altos y ricos funcionarios burgueses, la Policía Interna, la política cultural cubana de los setenta y ochenta y el uso de las máscaras ideológicas de los cubanos. Además, hay una serie de observaciones críticas ocasionales, a veces llenas de ironía y humor como, por ejemplo, las ya conocidas acerca de 'la piloto' del Candito el Rojo, con las cuales, supuestamente, "[1]a eficiencia regresaba a la ínsula” (Máscaras 20), la existencia de las "diplotiendas" (Máscaras 93), donde los ricos consiguen todo, el mal estado de las calles "cada vez más llena[s] de baches" y de "las casas carcominadas" (Máscaras 84), el mal tabaco para los funcionarios medios y bajos en un país exportador de buenos cigarros y, finalmente, la llegada atrasada de la cuota del café (cfr. 27), etc.

Respecto al funcionamiento de la Policia Interna, ya se mencionó arriba la inseguridad y el miedo que provoca en los funcionarios de la Central de Policía que se sienten observados y vigilados. El mayor Rangel, por ejemplo, le recomienda en Máscaras al Conde no hablar dentro del edificio de la

11 En este contexto tampoco hay que olvidar que la figura quijotesca del Conde, que con su falta de sentido de la realidad material "ve el mundo desde su perspectiva romántica, en la que existen códigos sagrados como son la amistad, el amor, la fidelidad, la decencia y la creencia en el poder salvador de la literatura", es acompañado en todos sus casos policiales por Manolo Palacios que "siempre es más directo, más material, como Sancho, pues ve en la realidad los molinos que Conde o Quijote confundirían con gigantes" (Padura citado en Uxó, "Entrevista..." 32-33). La vida de ambos cambia a fines de los noventa. Mientras el Conde abandona la policía y se dedica a la compra y venta de libros viejos, oficio que sigue practicando en 2003 (cfr. La neblina del ayer), en forma paralela, su antiguo ayudante, el sargento Palacios asciende a teniente en Adiós, Hemingway (2001) y a capitán en La neblina del ayer (cfr. ibid. 31). Según Michelena, el "ayudante Palacios es un Watson postmoderno, una parodia del policía" (46). 
Central con Manolo sino afuera: "Si alguien se entera de que yo te dije eso, al que parten los cojones es a mí" (107). Según la experiencia de Manolo en su citación, los funcionarios de la Policía Interna "sabían ya todas las respuestas, [...]. Es una cosa increible, viejo: saben hasta cuántos cigarros nos fumamos en el día, [...]: nos tienen retratados y saben todo lo que hacemos y lo que no hacemos, y todo les interesa" (115-16). Uno de los métodos de la Policía Interna para saber todo es la infiltración de personas en la Central de Policía, como por ejemplo la simpática secretaria "Maruchi", que por gran sorpresa del mayor y del Conde "también es de Investigaciones Internas y fue el agente que sembraron aquí para que empezara toda la investigación [...]" (190). Aquí se cumple el diagnóstico de Alberto Marqués, ya que los policías, según él, "interrogan y meten presa a la gente", cumpliendo de esta forma con su "vocación represiva y cruel" (95), convirtiendo al país en un Estado policial. Si agregamos a esta actitud policial de vigilancia y castigo el trabajo de control y vigilancia de los $\mathrm{CDR}^{12}$, no cabe duda de que Cuba puede ser denominado un "Panóptico insular" (Fernández 2) en el sentido que le da Foucault en su libro Vigilar y castigar $(1975)^{13}$. Padura, así, denuncia, en esta novela, que en Cuba se vive en un estado de constante vigilancia.

También en Paisaje de otoño, una de las críticas más importantes se dirige a la institución policial a la cual Mario Conde pertenece. De hecho, justamente decide renunciar, debido a la corrupción de sus compañeros y a que esto le costó la salida al mayor Rangel. Se trataba de la investigación y destitución de muchos de sus compañeros, personajes en quienes confiaba y que, finalmente, resultaron ser unos delincuentes, lo que para nuestro teniente

12 "Los Comites de Defensa de la Revolución fueron establecidos en 1960 en respuesta a un atentado contra la vida del dictador. Según Teresa Sánchez, Directora Nacional de los CDR en 1974, la mayor responsabilidad de los Comites de Defensa, incluso catorce años después de su institución, seguía siendo la vigilancia revolucionaria y la educación de las masas en la ideología revolucionaria [...], función que en 1980, según Castro, continuaba siendo su mayor contribuición a la defensa del régimen: [...]. Los 'ojos' están en todas partes ya que, desde su institución, la membresía crece exponencialmente a medida que la dictadura solidifica su hegemonía política en la isla. De un millón de inscritos en 1963, [...] la cifra total crece a 3.5 millones en 1974 [...], y, según Castro, llega a 5.5 millones en 1980 [...], o un $80 \%$ de la población" (Fernández 8).

13 Según Foucault, desde el siglo XVIII, los sistemas de disciplina ejercen el control sin tocar el cuerpo de los sujetos. La figura arquitectónica y el concepto del 'panóptico' explica el funcionamiento de los excluidos frente al poder ya que actúan como si fuesen permanentemente vigilados. 
es peor que ser un delincuente común: "colegas de veinte años traicionándose enconadamente, viejos policías intachables descubiertos como malandrines consuetudinarios, casos sepultados bajo cantidades insospechadas de billetes, favores consentidos a cambio de las más disímiles mercancías: desde un sexo joven y abultado hasta un título universitario obtenido sin asistir a clases" (28). El mismo Rangel lo felicita por su salida, ya que la policía es un círculo que termina corrompiendo a cualquiera: "No jodas Conde. Lo que iba a decirte es bien sencillo: es mejor que te vayas de la policía antes de que no tengas remedio. Ahí vas a terminar siendo un cínico, o un insensible, o un mal tipo al que le da igual ver un muerto que tomarse un refresco" (206). Decepcionado de sus compañeros y, también, de quienes los han hecho caer solo por taparse las espaldas, Mario Conde ha sabido mantener una ética que no transa a este respecto. Y pide su baja justamente por eso, porque no soporta la mentira ni el engaño, como dice él: " $[\mathrm{P}]$ orque no quiero seguir revolviéndome en la mierda, en la mentira y la falsedad. Porque no resisto la idea de que la mitad de los policías que fueron mis compañeros durantes diez años, entre los que había gentes en las que yo creía, hayan sido expulsados justa o injustamente. Y porque quiero tener una casa frente al mar para ponerme a escribir. Quiero escribir una historia escuálida y conmovedora" $(200)^{14}$.

Las consecuencias perjudiciales del permanente vigilar y castigar en la Policía Interna, se pueden constatar también en el ámbito cultural, por ejemplo, cuando se intenta 'parametrar' a los artistas homosexuales en los años setenta, en Máscaras.

Es decir, al comienzo de los setenta "se legislaba jurídicamente sobre el 'homosexualismo ostensible y otras conductas socialmente reprobables..."' (Máscaras 148). Según Padura, en este tiempo "[s]e suponía que por ser homosexual el individuo no podía ser actor de teatro o bailarín de un grupo de danzas: es decir, no cumplía con los 'parámetros' ideológicos para ser un artista que trabajara para el pueblo" (citado en Epple 50). La víctima por excelencia de esta nefasta política cultural cubana, resulta ser Alberto

14 En Adiós, Hemingway (2001), Mario Conde es "recuperado por sus antiguos compañeros de la policía y convertido en un curioso y eventual detective privado en Cuba", que intenta saldar "sus cuentas con este escritor. Cuentas que provenían desde su infancia, cuando su abuelo lo llevó a las embarcaciones donde estaba Hemingway y lo vio desembarcar". Por admiración al escritor norteamericano, Mario Conde hace todo lo posible por "salvaguardar y proteger el buen nombre y la memoria de Hemingway" (Sumalavia 178). 
Marqués, "la máscara que esconde la figura de Virgilio Piñera" (Rosell 454). En dicha entrevista, Padura reconoce que la novela Máscaras

[...] sobre todo está pensada como homenaje a Virgilio Piñera y a lo que sufrió durante los años setenta cuando estuvo apartado de los centros culturales importantes, sumido en el ostracismo. Es una novela de homosexuales, de máscaras, centrada en ese fenómeno del travestismo moral que se ha vivido en Cuba en este tiempo, en que las personas dicen algo y piensan otra cosa, obligadas por las circunstancias (citado en Epple 58).

Detengámonos en la primera parte de esta importante cita y precisemos lo que este intento de parametración significó para este artista. Según las palabras puestas por Padura en boca de Alberto Marqués, éste sufrió el aludido proceso de la siguiente manera:

Mire, hace dieciocho años, cuando corría el año del señor de 1971, yo fui parametrado y, claro, no tenía parámetro de los que pedían. Se imagina eso, ¿parametrar a un artista, como si fuera un perro con pedigree? Casi es cómico, si no hubiera sido trágico. [...] Bueno, empezó toda aquella historia de la parametración de los artistas y me sacaron del grupo de teatro y de la asociación de teatristas y después de comprobar que no podía trabajar en una fábrica [-...-], pues me pusieron a trabajar en una biblioteca pequeñita que está en Marianao, clasificando libros (Máscaras 49).

También el Conde sufrió las consecuencias del "ejercicio castrante de la reeducación" (Máscaras 60) que controla a través de la censura y que castiga brutalmente. Por eso siente mucha solidaridad con el censurado y castigado teatrista Alberto Marqués. En el caso del Conde se prohibió solamente la publicación de su cuento y cerraron la revista La Vivoreña, acusándolo a él y sus amigos por las razones que ya se citó arriba. Según el Marqués, los peores o mejor dicho: "[1]os jodidos" son en este proceso de la censura cultural "los comisarios voluntarios, los perseguidores espontáneos, los delatores sin sueldo, los jueces por afición, todos esos que se creen dueños de la vida, del destino y hasta de la pureza moral, cultural y hasta histórica de un país..." (Máscaras 95). Ellos son solamente comparables a un "tribunal inquisidor" (Máscaras 96) medieval que exige revisiones y rehabilitaciones o castiga brutalmente. 
Volviendo ahora a la segunda parte de aquella cita importante de Padura, hay que recalcar que, según él, esta situación de permanente vigilancia, censura y castigo obliga a los cubanos a usar máscaras ideológicas: "homosexuales que aparentan no serlo, resentidos que sonríen al mal tiempo, brujeros con manuales de marxismo bajo el brazo, oportunistas feroces vestidos de mansos corderos, apáticos ideológicos con un utilísimo carnet en el bolsillo" (Máscaras 149-50). Según Alberto Marqués, la gente maneja estas "máscaras como si fuesen sus propias caras" (Máscaras 202), pero son especialmente los travesti, quienes tienen la capacidad de consumar el "teatro consciente que se ha soñado desde los días de Pericles: la máscara hecha personaje ${ }^{15}$, el personaje tallado sobre el físico y el alma del actor, la vida como representación visceral de lo soñado..." (Máscaras 91).

La máscara más importante en esta novela es, probablemente, aquella del víctimario Faustino Arayán, quien a través de ella aparentó durante varias décadas ser un gran rebelde revolucionario para obtener ventajas políticas y convertirse en uno de los altos funcionarios ricos y poderosos. Su arribismo social lo llevó no solo a falsificar documentos que certificaran su postura ideológica 'políticamente correcta', sino también a delatar, en París, a sus compatriotas Alberto Marqués y el Recio, subiendo de esta forma en el escalafón político a costa de la caída de otros. No sorprende, por eso, que Padura convierte a este "mal bicho" (Máscaras 207) en asesino de su propio hijo Alexis, cuya homosexualidad nunca pudo aceptar. Tratándolo como leproso en su propia casa, odiándolo, rechazándolo y, en cierta medida, abandonándolo afectivamente, Faustino Arayán resulta ser, al final, el principal responsable del deseo de Alexis de no haber nacido y de autoeliminarse a través de la intervención de su padre, a quien le da un motivo para matarlo, ya que lo amenaza con delatarlo ante las autoridades cubanas por falsificación de documentos que acrediten su espíritu revolucionario. El alto puesto político y el bienestar de la clase alta revolucionaria que vive, al igual que la anterior clase alta bajo el dictador Batista, en grandes y bellas mansiones en el barrio

15 Cfr. el hecho de que la palabra latina persona procede de la palabra 'prosopon' y significa justamente la máscara que los griegos usaron en su teatro. Interesante es, en este complejo contexto psicológico y sociológico, también el hecho de que la Sociología de los roles (cfr. T. Parson y R. Dahrendorf) habla de los diferentes roles sociales que asumimos en diferentes momentos o ámbitos de nuestra vida social; dicho con otras palabras, las diferentes máscaras que usamos. 
Miramar, son conquistas burguesas a las cuales Faustino Arayán por ningún motivo está dispuesto a renunciar, aunque el precio de mantenerlas sea el asesinato de su hijo.

Lo insólito que plantea Padura en esta novela, que comprueba su asimilación polémica del género policial cubano anterior a él, es el hecho de que el criminal es aquí un miembro de la cúpula política de Cuba, lo que provoca inmediatamente, como ya vimos arriba, el intento de las autoridades políticas cubanas de protegerlo, bajarle el perfil al penoso asunto y, por ningún motivo, ponerlo en "un reclusorio con asesinos de todas las especies y aficiones, capaces de obligarlo a limpiar sus celdas y sus atrasos sexuales [...]" (Máscaras 191). Seguirá, por lo tanto, gozando de ciertos privilegios característicos de los que son 'más iguales'.

En Paisaje de otoño, Padura critica a otro alto funcionario rico, contrastando el hambre y la escasez que caracterizan a una buena parte de la isla, incluidos Mario Conde y la mayoría de sus amigos, con la opulencia de aquellos que se han enriquecido a costa de los bienes expropiados a la burguesía durante la revolución. El empobrecimiento de la mayoría y el enriquecimiento de unos pocos se manifiesta, claramente, en la conversación que mantiene el teniente Mario Conde con Gerardo Gómez de la Peña, un ex compañero de trabajo del asesinado Miguel Forcade. Gómez de la Peña es un hombre arrogante, que se jacta de poseer en su casa un Matisse original, adquirido a bajo costo y cuyo real precio es de más de tres millones de dólares, personaje que admite sin asco cómo administró el poder y al cual Mario Conde le pregunta:

Si puede volver a ser sincero conmigo, respóndame otra pregunta: ¿no le parece realmente bochornoso tener en esa pared de esta casa un cuadro millonario, comprado con su cargo, mientras allá abajo hay gentes que se pasan la semana comiendo arroz y frijoles después de trabajar ocho o diez horas y a veces no tienen ni una pared para colgar un almanaque? (Paisaje de otoño 57).

El lector se sorprende con la fría respuesta que le entrega el ex 'superministro':

-¿Por qué iba a abochornarme, precisamente yo, que soy un viejo retirado al que le gusta mirar ese cuadro? Por lo que veo teniente, usted no conoce muy bien este barrio, donde en casas tan confortables como ésta hay otros cuadros tan bellos como ése y adquiridos 
por caminos más o menos similares y donde se acumulan además esculturas de marfil y de maderas preciosas africanas, donde están de moda los muebles nicaragüenses, donde a las sirvientas se las llama 'compañeras' y se crían perros de razas exóticas que comen mejor que el sesenta por ciento de la población mundial y que el ochenta y cinco de la nacional... No, claro que no me abochorno. Porque la vida es como dijo el viejo congo: al que le cocó, le cocó. Y al que no le tocó, lástima, pero ese se jodió ¿no? (Paisaje de otoño 57-58).

Así, Padura critica el olvido de los ideales materialista-históricos ${ }^{16}$ y el consecuente egoísmo económico de los poderosos, y denuncia el hecho de que el poder corrompe de todas formas, pues aun quienes estaban a favor del régimen comunista buscaron enriquecerse individualmente.

Todos estos acontecimientos ya no ocurren en "la ciudad rítmica y folclórica de Cabrera Infante; ni en la ciudad mítica y mitológica de Lezama", sino en una ciudad de La Habana "con todos sus eslabones en crisis, [...] una Habana de la destrucción, los barrios marginales, los solares y las aguas albañales; una ciudad donde la superpoblación conlleva los males de siempre; una ciudad donde se pierden valores arquitectónicos y morales" (Valle Ojeda 197-98). En su último libro, Padura muestra incluso "una Habana más agotada, más vencida y, en ciertos sectores, más envilecida" (citado en Uxó, "Entrevista..." 29). Padura dice vivir un cierto extrañamiento en relación con su actual ciudad natal porque él creció "en una ciudad de barrios, y [él] naci[ó] en uno de ellos, donde todavía viv[e]: Mantilla. Este barrio, en el que nacieron [su] bisabuelo, [su] abuelo, [su] padre, y nac[ió] [él], es como un micromundo, como una célula que se integra al cuerpo mayor de la ciudad, pero que a la vez tiene su entidad propia" (citado en Uxó, "Entrevista..." 35). También el Conde es de este barrio más humilde, que es en cierto sentido un lugar de privilegio dentro del macromundo de la ciudad de La Habana, el cual contrasta tanto con los barrios más 'aristocráticos' como Miramar o El Vedado, donde suceden los crímenes, como del barrio marginal donde vive su amigo Candito El Rojo.

16 Esto se ve, por ejemplo, claramente al final de la novela cuando "el Conde se metió en la habitación de Riverón. Buscó en el clóset, debajo de la cama, y revisó algunos libros de economía socialista, durmientes y empolvados, tan olvidados como el ideal planificado que proponían como futuro real, cercano, dialécticamente histórico" (Paisaje de otoño 185). 
Resumiendo, podemos constatar que Padura, utilizando a menudo un lenguaje predominantemente coloquial y ‘duro', un típico "lenguaje habanero", "un lenguaje altamente desenfadado que se adecua a los diversos entornos por donde transita el relato" (Michelena 49), nos presenta su ciudad natal. Además, recurriendo a expresiones que comprueban su ironía y humor, y presentando como intertextos, por ejemplo, la tragedia griega (cfr. período de Pericles, Édipo y la "hybris" (Máscaras 200), a Homero (cfr. María Antonia, "la de los pies alados") y la Biblia (cfr. el capítulo de la Transfiguración de Jesús), ha evitado, sin duda, como se ha propuesto en 1990, los errores de sus colegas cubanos anteriores a él y ha escrito novelas que él llamaría, sencillamente, buena literatura, creando en el policía Mario Conde "un personaje de validez literaria" (citado en Epple 57) y valiosa complejidad dramática. Al parodiar y, ante todo, polemizar abiertamente (cfr. Bajtin) con la policial cubana anterior, Padura crea impactantes novelas policiales híbridas que merecen un lugar destacado dentro del policial latinoamericano. En ellas asimila -en forma híbrida y paródica (cfr. Bajtin) y bastante pareja-elementos tanto del género policial clásico de enigma (cfr. el crimen misterioso; la investigación realizada por un teniente; la aclaración del caso, es decir, la identificación y el arresto del criminal; la casi total falta de violencia física en los interrogatorios) como del género policial negro (cfr. el lenguaje coloquial 'duro'; la relación del Conde con las mujeres; la fuerte crítica social (de los ricos y poderosos) y política (del Estado cubano) y, ante todo en los ultimos textos, del género policial anti-detectivesco (postura crecientemente posmoderna frente a la verdad, la fe y la justicia; un investigador frustrado, jodido y anti-héroe; un discurso a menudo irónico).

\section{BIBLIOGRAFÍA}

Bonfantini, Massimo A. \& Proni, Giampaolo. “To Guess or not to Guess?”. El signo de los tres. Dupin, Holmes Peirce. Eds. Eco, Umberto \& Thomas A. Seboek. Barcelona: Lumen, 1989. 164-184.

Chavarría, Daniel. Joy. La Habana: Editorial Arte y Literatura, 1977.

Dahrendorf, Ralf. Homo sociologicus: un ensayo sobre la historia, significado y crítica de la categoría del rol social. Trad. José Belloch Zimmermann. Madrid: Instituto de Estudios Políticos, 1973.

Epple, Juan Armando. "Entrevista: Leonardo Padura Fuentes”. Hispamérica 24. 71 (Aug. 1995): 49-66. 
"Las tramas de Adiós, Hemingway, de Leonardo Padura". The Detective Fiction of Leonardo Padura Fuentes. Ed. Carlos Uxó. Manchester (Inglaterra): Manchester Metropolitan University Press, 2006.171-77.

Fernández Pequeño, José M. "La novela policial revolucionaria ante sí misma (1976-1986)”. Crítica sin retroceso. Por Fernández Pequeño. La Habana: Unión, 1994. 24-50.

Fernández, Manuel. "La figura del mimo en Máscaras de Leonardo Padura Fuentes” (Julio 2002). 10 diciembre 2004. http://www.lehman.cuny.edu/ ciberletras/v07/fernandez. $\mathrm{html}$

Michelena , José Antonio. “Aportes de Leonardo Padura a la literatura policial cubana”. The Detective Fiction of Leonardo Padura Fuentes. Ed. Carlos Uxó. Manchester (Inglaterra): Manchester Metropolitan University Press, 2006. 38-53.

Nogueras, Luis Rogelio. “Joy: algo más que un perfume”. Por la novela policial. Por Nogueras. La Habanna: Ediciones Unión, 1982. 59-64.

Parson Talcott (ed.), La sociología norteamericana contemporánea: perspectivas, problemas, métodos. Trad. O. A. Muslera. Buenos Aires: Paidós, 1969.

Padura F., Leonardo. "Modernidad y posmodernidad: La novela policiaca en Iberoamérica". Modernidad, posmodernidad y novela policial. Por Padura. La Habana: Ediciones UNIÓN, 2000. 117-57.

"En Cuba no se reprime a los escritores, se les margina". Encuentro en la red-Diario independiente de asuntos cubanos (8 de octubre de 2004): 1. http://www.cubaencuentro. com/cultura/noticias/20041008/a44d995f16d4ab9f91e8ff372c476.html

Pérez, Genaro J. "Motivos repetitivos en Vientos de cuaresma de Padura Fuentes". The Detective Fiction of Leonardo Padura Fuentes. Ed. Carlos Uxó. Manchester (GB): Manchester Metropolitan University Press, 2006. 106-113.

Rodríguez Coronel, Rogelio. Novela de la Revolución y otros temas. La Habana: Editorial Letras Cubanas, 1983.

Rosell, Sara. "La (re)formulación del policial cubano: la tetralogía de Leonardo Padura Fuentes". Hispanic Journal. 21. 2 (Fall 2000): 447-58.

Sumalavia, Ricardo. "Tributos e ironías en el neopolicial latinoamericano en Adiós, Hemingway de Leonardo Padura”. The Detective Fiction of Leonardo Padura Fuentes. Ed. Carlos Uxó. Manchester (GB): Manchester Metropolitan University Press, 2006. 178-88.

Uxó, Carlos. "Entrevista con Leonardo Padura (Noviembre 2005)". The Detective Fiction of Leonardo Padura Fuentes. Ed. Carlos Uxó. Manchester (GB): Manchester Metropolitan University Press, 2006. 27-37.

"Introducción". The Detective Fiction of Leonardo Padura Fuentes. Ed. Carlos Uxó. Manchester (GB): Manchester Metropolitan University Press, 2006. 9-14.

Valle Ojeda, Amir. "La nueva ciudad cubana (y/o La Habana otra) en la novelística negra de Leonardo Padura". The Detective Fiction of Leonardo Padura Fuentes. Ed. Carlos Uxó. Manchester (GB): Manchester Metropolitan University Press, 2006. 192-99.

Vilches, Freddy. "Descorriendo el velo: apariencia y realidad en Las cuatro estaciones de Leonardo Padura". The Detective Fiction of Leonardo Padura Fuentes. Ed. Carlos Uxó. Manchester (GB): Manchester Metropolitan University Press, 2006. 65-87. 